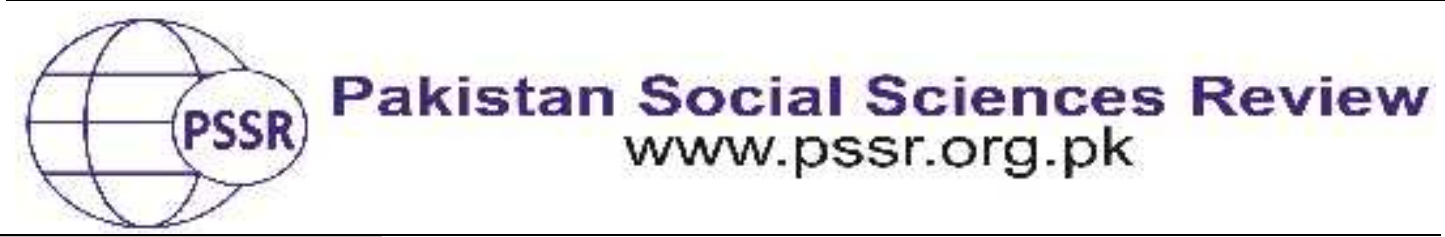

RESEARCH PAPER

\title{
Endorsement of Diverse Cultures in Less Developed Areas: A Study to Understand the Effects of Cable Television in Southern Punjab
}

Dr. Imran Muslim ${ }^{1}$ Dr. Muhammad Shabbir Sarwar ${ }^{2}$ Dr. Amir Mehmood Bajwa ${ }^{3}$

1. Assistant Professor, Department of Mass Communication, Government College University, Faisalabad, Punjab, Pakistan.

2. Assistant Professor, Institute of Communication Studies, University of the Punjab, Lahore, Punjab, Pakistan.

3. Assistant Professor and Chairman, Lahore Garrison University, Lahore, Punjab, Pakistan

\begin{tabular}{|c|c|}
\hline PAPER INFO & ABSTRACT \\
\hline $\begin{array}{l}\text { Received: } \\
\text { Iulv 29, } 2020\end{array}$ & This research study was conducted to study the effects of \\
\hline Acce & especially when it is available with multi-channel \\
\hline r 05, 2020 & less developed areas. Population for this study was \\
\hline Onl & South of Punjab Province in Pakistan, which is a less developed \\
\hline September 30, 2020 & area comparatively. A sample size of 300 was selected by using \\
\hline $\begin{array}{l}\text { Keywords: } \\
\text { Cable TV, } \\
\text { Cultural Invasion, } \\
\text { Demographic, } \\
\text { Variations }\end{array}$ & $\begin{array}{l}\text { multi-stage cluster sampling technique. Data was collected } \\
\text { through survey questionnaire. Results of the study revealed that } \\
\text { consumption time for TV contents by the respondents of the } \\
\text { selected area was quite reasonable. People agreed not only to }\end{array}$ \\
\hline Corresponding & give weightage to the different cultural values but also adopted \\
\hline $\begin{array}{l}\text { Author } \\
\text { shabbir.ics@pu.edu. } \\
\text { pk }\end{array}$ & $\begin{array}{l}\text { many of the traits. It was concluded that television has got the } \\
\text { power to influence any type of audience, regardless of their age, } \\
\text { education level and other demographic variables. }\end{array}$ \\
\hline
\end{tabular}

\section{Introduction}

Human communication is studied by the social scientists with a great zeal and devotion since the known history of mankind. Although people used the symbolic and nonverbal communication of human communication is divided into two main categories. First one is called rhetorical and the latter is denoted as relational communication (Fitch, 2010).

Since rhetoric communication addresses the influence mainly so it has become the main point of interest for the scholars in media studies. Pace and intensity of human communication is increased through different tools of Mass communication. Out of these organs of Mass Communication Television has got the special placement due to its divergence and access to the public (Stacks \& Salwen, 2009). 
Communication through mass media is usually symbolic in nature and these symbols and signs are influenced by or derived from the Culture of societies. Human interaction and culture are not two different entities rather both complement each other. Level of influence of foreign culture may vary in different groups of people due to many reasons but mass media, especially Television work as catalyst to enhance this acceptance of diverse cultural traits (Gudykunst, \& Kim 2003).

Mass media in its advance forms travel through different regions with varied pace. Less developed areas got this opportunity to enjoy the new trends inhuman communication quite late. So it has become a potential area of investigation for the researchers to differentiate the effects of media in developed and deprived societies.

In the twenty-first century television is experiencing a technical and formal transmutation. Between the 1950s and 1990s television was systematized as a controlled and principally national medium reliant on the unusual tool of electromagnetic frequencies. Towards the end of the era it was a source of profusion, with loads of satellite, cable networks, and digital channels accessible to almost every house hold. Television once gave the spirit of a nationally endorsed culture. Now it is essentially part of an international industry, progressively out of reach of the governmental control.

The digitalization of the television industry stimulates competition in the market in two ways. First, digitization allows multiple channels to be transmitted using limited radio waves. Second, the digitization of communications infrastructure blurs the line between telecommunications and broadcasting, as the digital format can be transferred to any type of digital communications infrastructure, such as mobile phones. Thus, digitization allows any communications service provider to enter the broadcasting market. Mobile television has become a reality. The popularity of mobile TV is growing due to the growing penetration of mobile devices.

\section{Cultural Adaptation and Mass communication}

The term "culture" has different meanings, which claim to be a way of life and how people relate to each other. As per views of some Social scientists, culture is the education of people, because culture updates people about how to live in society and how to apply certain morals in society. Culture empowers people to endure. But due to globalization of Mass media culture in underdeveloped countries is being effected (Tariq, 2004).

Culture accentuates all characteristics of human life, such as "lifestyle" and "interaction with other people". In fact, our thought process is also a depiction of our culture, since culture communicates us everything. Due to a huge role of media, culture of different societies alters and is shared by members of the social system, also (Camella, 2007). 
There are two different types of culture that deal with tangible and intangible culture. Tangible culture refers to things or objects that have a physical existence, while intangible culture deals with aspects that do not have a physical reality. But media has power to influence both types of culture (Bukhari, 2002).

Thompson \& Bryant (2002) conducted a research study on the advent of Dish antenna, connecting the people with rest of the world through satellite technology. They analyzed that audience although took interest in this new technology due to ts diverse content but on the other hand there was a strong apprehension that being an Islamic country, Pakistan does not afford such type of bold content. As a whole, the respondents of the study were afraid of the cultural invasion through Dish antenna.

On the contrary, Butt (2005) in his research accentuated the viewpoint of analyzing the projection of the "Hinduism" as a religion in Indian soap operas, convincingly not only showing the general proportion of this projection, but also unfolding it separately. The researcher found that soap opera evidence directly or indirectly illumines Hindu religion as much as possible by highlighting the types and names of "gods and goddesses", religious stanzas, words and history, numerous religious scenes, sounds and observances.

Some religious scenes are necessary for the narrative, but in most cases the projection is not necessary. He added that their most popular shows project Hindu religion with such an intensity that can easily affect viewers of another religion. Because these soap operas are not seen all over the country, but all over the world. In this study, the researcher used a content analysis method to test the projection of the Hindu religion in Indian TV series. For this, a quantitative analysis of the content of the TV series of the Indian news channel was chosen. The researcher also provided a plan for the future of other researchers, including the fact that this study should first be supported as an effect study to test the impact of this likelihood on Pakistani Muslims, especially kids and young ones. Following this effect study, a new study on the behavior of cable users and non-users can also be performed.

Yoshii H. (2001) conducted the study "Invasion of Indian Culture through Films." This study evaluated the impact of Indian films on high-end wedding / celebrations in Lahore, Pakistan. The sample size for this study was 100 respondents. The survey results showed that the majority of respondents $(87.9 \%)$ watched Indian and British films on cable TV. $92.2 \%$ of audience agree that Indian films display attractive wedding customs, hairstyles, makeup, clothing, jewelry and lifestyle. Twenty percent of the respondents agree that high-profile wedding events the track patterns shown in Indian films. Almost $75 \%$ of the respondents admitted that Indian films influenced the clothes of the newly married couples and their family members. Likewise, the makeup and hairstyle of bride jewelry and stage decor have also been transformed due to Indian movies.

In a study conducted to find out the effects of cable TV on viewers, it has been found that "the Indian content of the cable TV channel has influenced the social 
and cultural norms and values of Pakistani youth." The imagination displayed on these channels was the main reason for attracting students and the new Pakistani generation (Zia, 2007).

Numerous research studies have proved that Content disseminated through multi-channel cable TV system put a great impact on the audience and people not only endorse the new cultural indicators but also accept these slowly and steadily.

\section{Material and Methods}

Intentions were to collect a comprehensive feedback from the requisite inhabitants so in this study, survey technique has been incorporated to acquire the data. A big but dissimilar and widely spread population was chosen. The survey has supported the researchers in gathering information directly from the "cable television viewers" so that a suitable investigation could be made by comparing their lives.

The stratified sampling technique was used to approach the respondents who really represent the different population with varied characteristics. These strata include Urban Areas, Sub Urban areas and Villages. A sample size of 300, having age group of 15-65, was taken with the option of replacement of undesired or unwilling respondents. The data collection tool, used was survey questionnaire. In designing the instrument grounded on the reviewed literature and the "research gap" it was found, the questionnaire aimed to identify the kinds of different TV channels watched by residents of South Punjab. What they think of the use of these channels in their homes, what they consider to the advantages or disadvantages of cable television and for which reasons they will consider using cable TV or will stop using it.

\section{Results and Discussion}

Data was collected, mostly by using a five-point scale, in order to facilitate the respondents for their feedback. Data is presented with the help of tables and graphs and is elaborated accordingly.

Table 1

Socialization with the relatives

\begin{tabular}{ccccccc}
\hline & Female & $\mathbf{0}$ & Male & $\mathbf{\%}$ & Total & Total $\%$ \\
\hline Very Often & 12 & $04 \%$ & 21 & $07 \%$ & 33 & $11 \%$ \\
\hline Often & 36 & $12 \%$ & 42 & $14 \%$ & 78 & $26 \%$ \\
\hline Really & 30 & $10 \%$ & 27 & $09 \%$ & 57 & $19 \%$ \\
\hline Sometime & 39 & $13 \%$ & 21 & $07 \%$ & 60 & $20 \%$ \\
\hline Never & 33 & $11 \%$ & 39 & $13 \%$ & 72 & $24 \%$ \\
\hline Total & 150 & $50 \%$ & 150 & $50 \%$ & 300 & $100 \%$ \\
\hline
\end{tabular}


Above Table shows that from total of $11 \%$ respondents, $04 \%$ of females and $07 \%$ of males responded that they visit their relatives very often. $12 \%$ females and $14 \%$ males were from total of $26 \%$ responded that they often visit their relatives. The ratio of respondents to given statement was $10 \%$ females and $09 \%$ males from total of $19 \%$. The respondents who visit sometime were $13 \%$ females and $07 \%$ males from total of $20 \%$ respondents. From total of $24 \%$ respondents, $11 \%$ females and $13 \%$ males were of the view that they never visited their relatives.

Table 2

Decrease in frequency of outing with friends and family

\begin{tabular}{ccccccc}
\hline & Female & Female $\%$ & Male & Male $\%$ & Total & Total \% \\
\hline Strongly Agree & 18 & $06 \%$ & 12 & 04 & 30 & $10 \%$ \\
\hline Agree & 42 & $14 \%$ & 39 & $13 \%$ & 81 & $27 \%$ \\
\hline Disagree & 30 & $10 \%$ & 33 & $11 \%$ & 63 & $21 \%$ \\
\hline Strongly Disagree & 39 & $13 \%$ & 39 & $13 \%$ & 78 & $26 \%$ \\
\hline Feel Neutral & 21 & $07 \%$ & 27 & $09 \%$ & 48 & $16 \%$ \\
\hline Total & 150 & $50 \%$ & 150 & $50 \%$ & 300 & $100 \%$ \\
\hline
\end{tabular}

Table 2 shows that from total of $10 \%$ respondents, $06 \%$ of females and $04 \%$ of males were strongly agree to this question. 14\% females and $13 \%$ males were from total of $27 \%$ respondents. The respondents who were disagree were $10 \%$ females and $11 \%$ males from total of $21 \%$ respondents. From total of $26 \%$ respondents, $13 \%$ females and $13 \%$ males were strongly disagreeing with the given question.

Table 3

Consideration of TV characters as real

\begin{tabular}{ccccccc}
\hline & Female & $\mathbf{0}$ & Male & $\mathbf{\%}$ & Total & Total $\%$ \\
\hline Strongly Agree & 60 & $20 \%$ & 33 & $11 \%$ & 93 & $31 \%$ \\
\hline Agree & 27 & $16 \%$ & 48 & $09 \%$ & 75 & $25 \%$ \\
\hline Disagree & 15 & $05 \%$ & 12 & $04 \%$ & 27 & $09 \%$ \\
\hline Strongly Disagree & 36 & $12 \%$ & 24 & $08 \%$ & 60 & $20 \%$ \\
\hline Feel Neutral & 12 & $04 \%$ & 33 & $11 \%$ & 45 & $15 \%$ \\
\hline Total & 150 & $50 \%$ & 150 & $50 \%$ & 300 & $100 \%$ \\
\hline
\end{tabular}

Question about the Characters of TV plays was responded in an interesting way. Values of the table shows that from total of $31 \%$ respondents, $20 \%$ of females and $11 \%$ of males were strongly agreed to this question. $16 \%$ females and $09 \%$ males were from total of $25 \%$ respondents. The ratio of neutral respondents to given statement was $04 \%$ females and $11 \%$ males from total of $15 \%$. The respondents who were disagree were $05 \%$ females and $04 \%$ males from total of $09 \%$ respondents. From total of $20 \%$ respondents, $12 \%$ females and $08 \%$ males were strongly disagreeing with the given question. 
Graph 1

Imitation of Television characters

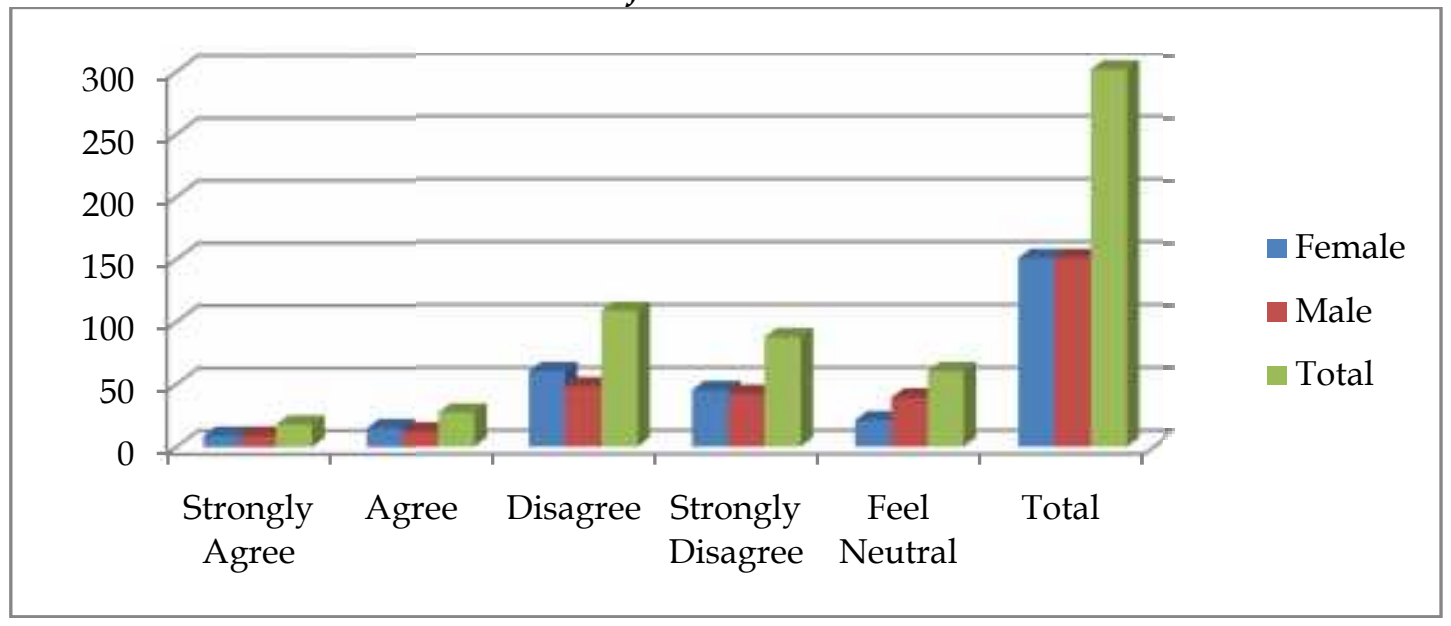

Graph shows that from total of 06\% respondents, $03 \%$ of females and $03 \%$ of males were strongly agree to this question. They were of the view that they consider the characters of TV similar to the real characters of their life and they agreed to imitate them. The respondents who were disagree were $20 \%$ females and $16 \%$ males from total of $36 \%$ respondents. From total of $29 \%$ respondents, $15 \%$ females and $14 \%$ males were strongly disagreeing with the given question. The ratio of neutral respondents to given statement was $07 \%$ females and $13 \%$ males from total of $20 \%$.

Table 4

Television as a source to know about new fashion trends

\begin{tabular}{ccccccc}
\hline & Female & $\mathbf{\%}$ & Male & $\mathbf{\%}$ & Total & Total $\%$ \\
\hline Strongly Agree & 51 & $17 \%$ & 36 & $12 \%$ & 87 & $29 \%$ \\
\hline Agree & 72 & $24 \%$ & 69 & $23 \%$ & 141 & $47 \%$ \\
\hline Disagree & 03 & $01 \%$ & 06 & $02 \%$ & 09 & $03 \%$ \\
\hline Strongly Disagree & 09 & $03 \%$ & 06 & $02 \%$ & 15 & $05 \%$ \\
\hline Feel Neutral & 15 & $05 \%$ & 33 & $11 \%$ & 48 & $16 \%$ \\
\hline Total & 150 & $50 \%$ & 150 & $50 \%$ & 300 & $100 \%$ \\
\hline
\end{tabular}

Since fashion is a big indication of culture so this question was directly relevant to the adoption of new trends via Television. More than two third of the research subjects agreed or strongly agreed that they adopt the new fashion after having inspiration from TV characters. The proportion of respondents with disagreement was negligible. However, $16 \%$ were undecided about such phenomenon. 
Graph 2

Adoption of other cultures through television

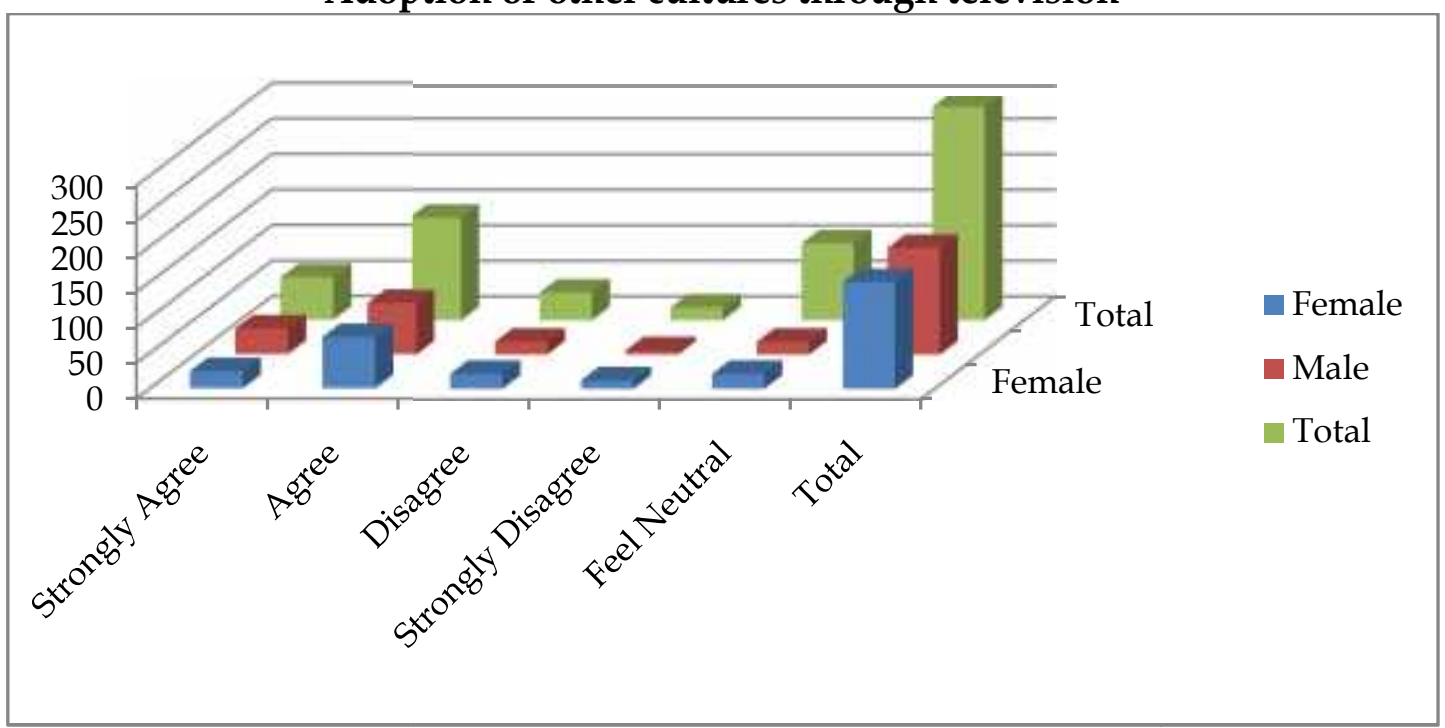

A large majority was agreed to the fact that T.V provided them with the opportunity to come across with the knowledge about culture of different societies. A very small number did not agree with this question of cultural dissemination through T.V.

Table 5

Relationship between education level and TV consumption

TV Viewing Time

\begin{tabular}{ccc}
\hline & \multicolumn{1}{c}{$\begin{array}{c}\text { Pearson } \\
\text { Correlation }\end{array}$} \\
\cline { 2 - 3 } $\begin{array}{c}\text { Education Level of } \\
\text { the respondents }\end{array}$ & Sig. & -.451 \\
\cline { 2 - 3 } & $\mathrm{N}$ & .587 \\
\hline
\end{tabular}

Table 5 shows a Negative relationship between the Level of education and time spent for TV viewing. We may infer that with the increasing education level, people may have change their priority or have become busy in their financial activities so they did not prove to be heavy viewer of Multichannel Cable Television. 


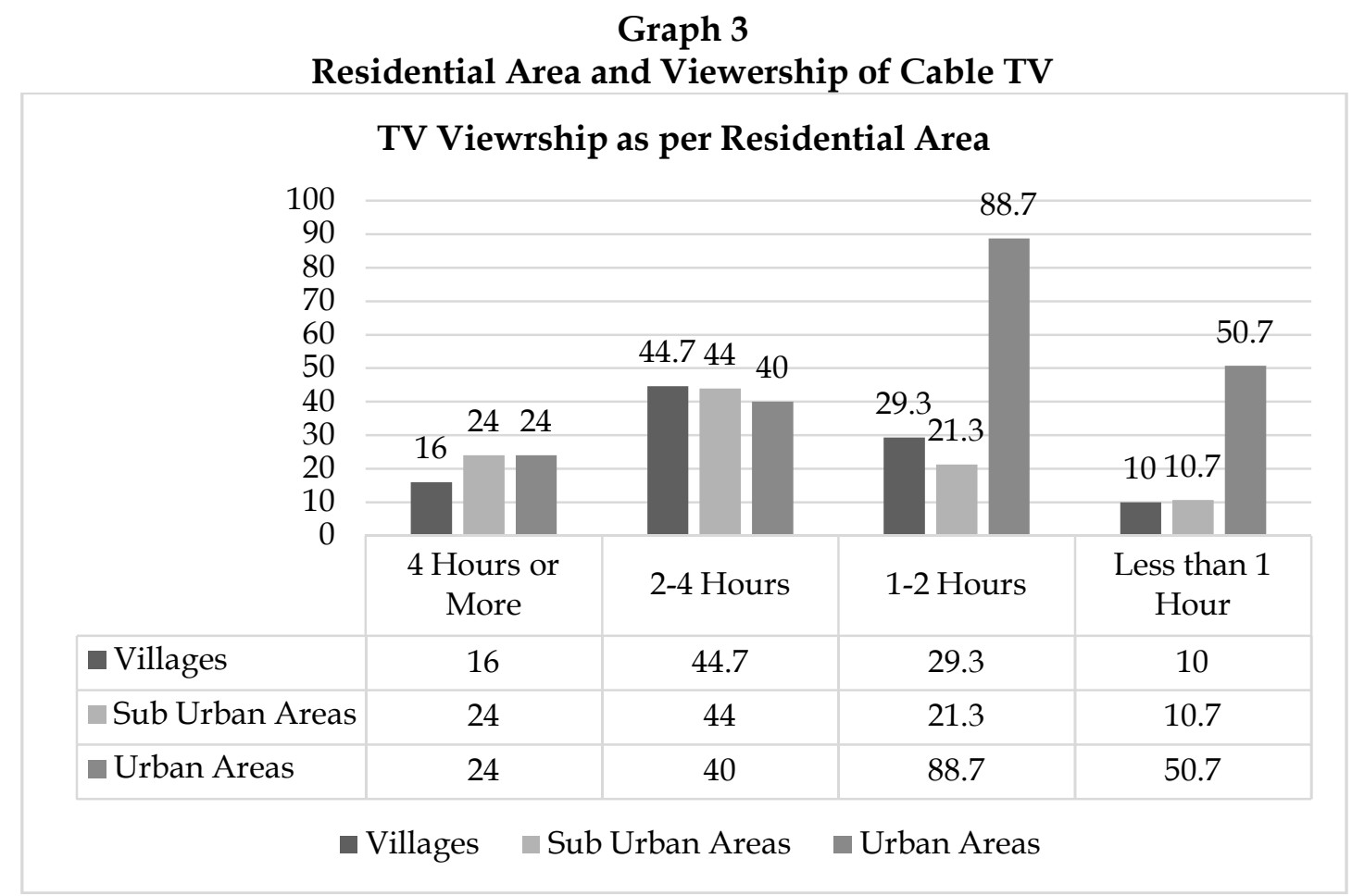

Since population of this study was divided into three strata. Above table and graph shows the distribution of T.V viewing trends of all three strata. Results clearly shows that in urban areas a large number of viewers opt the option of 1-2 hours / day. On the other hand, heavy viewers, were although less in numbers but they belonged to villages and suburbs.

\section{Miscellaneous Findings}

When analyzing the demographics of the respondents, the researcher found that the majority of respondents were between 36 and 45 years old. In Pakistan, this age group generally includes those who get married and are raising families.The family life of a Pakistani is the moment when he begins to discover his personality and conscious image of a character very closely connected with his home and family life.

This group is crucial for studying the influence of multi-channel cable TV on their lives, as it plays a vigorous part in the lives of their kids especially and their family generally. Although the study sample included all income groups, most were from the lower middle to upper middle classes and earned monthly up to Rs 20,000 or more. The results showed that most were married but were not on a job.

Demographic results established the aptness of the respondents for this study, as majority of them were accomplished and capable to realize various reports, even in non-native languages like English and Hindi. Most of them were remarried. 
Therefore, due to their social structure, they played a significant role in the life of their family. They have different buying capacity and were able to directly or indirectly sway the changes in their lifestyle caused by the media.

It is generally believed that extending the length of cable television viewership can increase the impact on viewers. Thus, the study also pursued to divulge the respondents' past involvement in cable television generally. The researcher therefore intentionally chose respondents who had been indulged in cable television for two years or more.

The results showed that the sample was relatively uniform in terms of the proportion of heavy and light viewers, a comparison of cable length and viewing levels showed that there was no significant relationship between them. However, the results showed that the highest percentage of active and bright viewers came from the type of audience who had a cable connection in the last two years. It can be determined that the level of visualization cannot be decided by the length of the cable TV Consumption.

Analysis of the relationship between research subjects based on age and degree of visualization showed that there was no significant inclination between them.

In conclusion, people of dissimilar ages have almost the same viewership patterns and spend almost the same amount of time on cable TV. However, an interesting discovery was presented in the category of light spectators. The investigation of the relationship among the respondents' education and the observation level showed that the proportion of active spectators was lower among graduates than among respondents with a secondary education level.

\section{Conclusion}

This study was conducted in Southern part of Punjab province, in Pakistan. Intentions of the researchers were to gauge the impact of multichannel Cable TV on the audience. It was found, as expected, that variety of content on different channels attracted the people and stole their time from social activities. Major components of culture, like dress, food habits, and traditions were adopted as per the characters ofTV plays. Results were almost similar in all three strata i.e. cities, suburbs and villages. However, increase in education level decreased the time consumption for TV programs.

Overall it was evident that Cable TV put its impact on the audience in accordance with the Contents. People followed the Characters, imitated them and did not show their resistance towards other cultures. 


\section{References}

Bukhari, B. (2002). The effect of television programmes on youth. Unpublished master's thesis, Department of Mass Communication, University of the Punjab, Lahore, Pakistan.

Butt, S. S. (2005). Projection of Hindu religion in Star Plus operas. Unpublished master's thesis, Department of Mass Communication, Lahore College for Women University, Lahore.

Camella, C. (2007). Para social relationships in female college student soap opera viewers today. Western Connecticut State University.

Fitch, T. (2010). The Evolution of Language. London: Cambridge University Press.

Gudykunst, W. \& Kim, Y. Y. (2003). Communicating with strangers: An approach to intercultural communication, 4th ed., 378. New York: McGraw Hill.

Khalid, S. (2001). Survey about the use of media by the students of Punjab University. Unpublished Master's Thesis Department of Mass Communication, University of the Punjab. Lahore.

Rehman, B. A. (2001). Theoretical framework. Challenges faced by Pakistan and role of religious magazines. Unpublished $M$. Phil thesis, department of Mass Communication. University of the Punjab. Lahore.

Stacks, D. \& Salwen, M. (2009). An Integrated Approach to Communication Theory and Research. New York: Routledge.

Tariq, H. (2004). Invasion of Indian culture through movies on high class marriage culture in Lahore. Unpublished Master's thesis, department of Mass Communication, Lahore College for Women University Lahore.

Thompson., \& Bryant. (2002). Fundamentals of media effects. New York: McGraw-Hill.

Yoshii, H. (2001). Transformation in media and society: laying the ground work for cultural ecology.

Zia, A. (2003). Cable television network in Pakistan: Introduction, development, prospects and dilemmas. Unpublished M. Phil Thesis, Department of Mass Communication. University of the Punjab. Lahore, Pakistan.

Zia, A. (2007). Effects of cable television on women in Pakistan: a comparative study of heavy and light viewers in Lahore. PhD Thesis, Department of Mass Communication. Lahore College for Women University, Lahore, Pakistan. 